\title{
El origen del mundo: \\ La Teología Feminista y la subversión de lo erótico
}

\section{Genilma Boehler}

Doctora en Teología e Historia por la Escuela Superior de Teología de la Iglesia de Confesión Luterana, San Leopoldo, RS, Brasil y profesora en la Universidad Bíblica Latinoamericana, San José, Costa Rica. Correo electrónico: genilma@ubila.net

Recibido: 9 de abril 2013 • Aprobado: 27 de junio 2013

\section{RESUMEN}

Se propone en este artículo discutir la Teología Feminista Latinoamericana desde la elaboración de nuevas preguntas, explorando nuevos significados, con claves propias hermenéuticas, desde las mujeres del continente latinoamericano y caribeño. Se propone a la desconstrucción de lo que se tiene como verdades únicas, exclusivas en la teología.

Palabras claves: teología feminista, sexualidad, erótico, sacralidad, hermenéutica.

\section{ABSTRACT}

This paper is proposed to discuss Latin American Feminist Theology from the development of new questions, explore new meanings, with our own hermeneutical key from the women of Latin America and the Caribbean. It is proposed that the deconstruction of what you have as unique truths, exclusive of the theology.

Keywords: feminist theology, sexuality, erotic, sacred, hermeneutics.

\section{Introducción}

Una antigua pintura del pintor francés Gustave Courbet, 1866, lleva el título $L^{\prime}$ Origine $d u$ Monde donde representa en su pintura, una vulva (Courbet, 2013). Lo que se conoce de la historia de esta pintura es que fue encargada a Courbet por un diplomático turco de nombre Khalil-Bey, antiguo coleccionador de imágenes eróticas femeninas. Curiosamente, Khalil-Bey la había instalado en un lujoso baño, que se mantenía cubierto por una cortina, donde pocos invitados la podían mirar (Brum, 2013: 1). Tal pintura ha pasado por varios dueños y en los registros de la historia del arte, siempre observase la reincidencia de que sus propietarios la mantenía oculta, detrás de una cortina o de otra pintura. En 1954, tal pintura fue comprada por Jacques Lacan, que la ha llevado a su casa de campo, y que pese el avanzado de su pensamiento psicoanalítico, ocultaba tal pintura con otra, del pintor surrealista André Masson, que serviría como una puerta corredera que retrataba una vulva abstracta. Solamente algunos tenían el permiso de Lacan para mirar la vulva real (Brum, 2013: 1).

Les puede parecer rara la imagen inicial para introducir un artículo, pero me gustaría invitarles a reflexionar sobre Teología Feminista, con la mirada crítica desde el proceso de colonización y ocupación que hemos sufrido en todo el 
continente latinoamericano y caribeño y las teologías que han legitimado este mismo proceso.. El detalle fundamental, prioritario que los conquistadores han impuesto en su proyecto hacia las mujeres de sumisión y abusos sexuales permanentes. Esta realidad, de dominación y opresión sexual, ha pasado por los siglos y hasta hoy, la violencia en contra de las mujeres y niñas es un fenómeno en gran escala, presente en nuestras culturas.

Por lo tanto, al recurrir a esta imagen de la pintura del siglo XIX de Courbet, lo que propongo es una mirada a la Teología Feminista desde la sexualidad, una teología contextual, que reivindica contextos y sujetos. Nada más simbólico para empezar la reflexión, que la vulva, simbólicamente ubicando desde donde los cuerpos de las mujeres latinoamericanas y caribeñas y su sexo, sus deseos, su erotismo han sido reducidos, y desde donde surge el empoderamiento para otra comprensión de vida y de Dios. Esto es posible, porque los métodos que han sido utilizados en las teologías feministas han permitido la insurgencia de otros fundamentos teológicos, que problematiza la política de representación religiosa androcéntrica que alberga un conjunto simbólico, ideológico pecaminoso (Althaus-Reid, 2006a: 66).

Paradojicamente, en las culturas latinoamericanas, a las mujeres nos han enseñando a esconder nuestras vulvas bajo discursos de fealdades, pecaminosidades y otros atributos, mientras que justamente a este punto llegan y llegaban los abusos y violencias en contra de nosotras mismas (Kottow, 2010: 3). Por un lado, el orden es de inhibir la libido, los deseos, las posibilidades de goces sexuales de las mujeres, bajo la imposición masculina del poder patriarcal, de roles predeterminados, y de la naturalización del control jerárquico del masculino sobre el femenino.

La subordinación y represión a las mujeres tiene que ver con la dominación sexual de las mismas, y naturalmente con la manipulación simbólica o real de sus cuerpos y de su sexo y la teología, así como doctrinas y reglas morales han servido para sostener tal realidad. Por esta razón, no se trata de algo atrevido o desconectado a un método, es valerse la vulva como una clave interpretativa. Al contrario, a la Teología Feminista Latinoamericana es posible aplicarle claves epistemológicas, utilizando el circulo de la hermenéutica sexual, que no significa una estricta relación circular entre las partes y el todo, fijando un solo modo de comprender e interpretar (Gadamer, 1999: 581), sino, lo que se propone es el movimiento de la intérprete frente a la tradición cristiana bíblica y teológica, en las cuales se encuentran elementos para su pre-comprensión. La teología feminista que se aplica al método de la sospecha sexual, posee la capacidad de subvertir los códigos teológicos, religiosos, desde el rescate de los discursos acerca de Dios, desde los códigos sexuales, de la pulsión de la vida y de los deseos, como también de la naturalidad del cotidiano y de otros significados desde el mismo cuerpo.

\section{¿Que hay entre sexualidad y la teología feminista de liberación?}

Uno de los desafíos para la Teología Feminista de la Liberación es "discernir acerca de la construcción de la sexualidad y los roles genéricos en Latinoamérica como subordinados políticos que han sido naturalizados por los procesos de colonización usando el orden sexual de Dios y de la Virgen en el continente" (Althaus-Reid, 2005: 104). En la teología cristiana, durante siglos y siglos, se sostuvo la idea de la virginidad de María disociada a la sexualidad, reafirmando el modelo heteronormativo del sexo para la reproducción únicamente (Althaus-Reid, 2005: 104), desagregado de la sensualidad, de la eroticidad, del goce. Según Althaus-Reid, "la mariología crea una historia de género a partir de un artefacto: una supuesta mujer que no tiene una actividad sexual reconocible es convertida en código sexual" (Althaus-Reid, 2005: 82). Esta es la idea básica de la cultura cristiana, reforzada por discursos teológicos, mariológicos, que veneran a un modelo femenino asexuado (Deifelt, 2010: 121), que refleja en las condiciones impuestas a las mujeres como modelo ideal a ser seguido.

Comprender a Dios desde la condición de las mujeres, muy específicamente de las mujeres 
empobrecidas de Latinoamérica, es tratar de romper con un círculo hermenéutico que ha naturalizado roles sexuales-sociales femeninos y masculinos desde la comprensión de un Dios imagen y semejanza con el masculino, o con un femenino asexuado. Se trata de rescatar los sujetos desde sus contextos, que reclaman por el discurso teológico que esté a su alcance y que responda a sus esperanzas. Porque la vida de las mujeres en este vasto continente, está marcada por la "subjetividad, incongruencias, vicios, interioridad y exterioridad, mezclados con esperanzas, pasiones, aventuras sexuales, probaciones financieras y experiencias en general, ocurre en el plan inestable de la materialidad temeraria" (Carvalhaes, 2010: 36).

El quehacer teológico es un acto de identificación con la simbología religiosa que exige posicionarse, comprometerse, cuestionar el orden político y social que se crea alrededor de las ideologías religiosas (Althaus-Reid, 2005: 76). Tales ideologías están marcadas por las ideologías sexuales que sostienen las estructuras económicas y políticas. Comprender la sexualidad como una clave metodológica, crítica, en el enlace del círculo de la sospecha hermenéutica, para la desconstrucción de los modelos de opresión, sumisión y exclusión (de clase, de género, étnica y de sexo) es un eje fundamental para la teología feminista latinoamericana. Tratase de paradigmas múltiples y simultáneos que posibilitan crear la percepción crítica y creativa en la articulación del discurso sobre Dios desde las mujeres y de los espacios ocupados por ellas mismas.

Por lo tanto, la teología feminista que trabaja con la clave hermenéutica de la sospecha sexual, es una teología profética, una vez que denuncia las raíces de la opresión heteronormativa, que conduce a una nueva comprensión de la realidad, inaugurando nuevos sentidos teológicos, antes ocultos bajo la represión, la censura, los perjuicios y clasificación de pecados. Es una teología que busca rescatar la vida, que va mas allá de la muerte, porque "no se trata [...] de la resurrección de los muertos de sus tumbas y cenizas, sino de abajo, de la gente oprimida que conoce diferentes muertes a diario: la muerte de la esperanza y los sueños, de los derechos, del amor y del deseo" (Althaus-Reid, 2005: 175). Como lo ha señalado Althaus-Reid, "[...] una teología honesta sexualmente, que refleje la vida de la gente y también la espiritualidad de nuestras culturas latinoamericanas, mucho más ricas y desafiantes que las impuestas por la Conquista" (Althaus-Reid, 2006a: 69).

\section{La sacralidad de lo erótico}

El elemento erótico y su relación intrínseca con el deseo y la sexualidad informa epistemológicamente acerca de una nueva dimensión hermenéutica para la construcción del discurso teológico feminista latinoamericano, desde el cuerpo, la vida cotidiana, las relaciones como lugar vital de construcción de poder y significaciones sociales y teológicas (Pereira, 2006: 7). ¿Pero, lo qué viene a ser lo erótico? Esta pregunta lo que hace es obligarnos a un reposicionamiento conceptual de lo erótico, que en general, se le atribuye al espacio íntimo, privado, personal, y no al público, colectivo, social, por estar inmerso en el ámbito del deseo.

Hay que comprender que el deseo habita en la subjetividad del sujeto, por su universo simbólico, que definitivamente está intermediado por la mente y por el cuerpo. Es también un elemento socialmente construido, que posee sus vínculos en las estructuras de poder que traspasan la experiencia. Luego siempre habrá tensión entre el privado y lo colectivo en la temática del erótico, que según Guattari, se trata de la creación de los "territorios existenciales" para la reinvención de la subjetividad (Guattari, 1991: 11-12). Para Guattari, es desde el deseo que la subjetividad establece el contacto con el mundo, con la exterioridad, lo que hace del deseo una construcción social (Guattari, 2005: 381). Pero hay un vacío en la sociedad, que al poner lo erótico vinculado con la sexualidad como un tema privado, se excluye la posibilidad de comprenderlo en las esferas públicas. Pero, es justamente en los espacios públicos que el erótico y la sexualidad se construyen: en el imaginario, la simbología, los tabús, los lenguajes, en lo que se enseña y en el que se aprende. 
En el discurso teológico feminista, lo erótico es abordado como deseo, como impulso, como fuerza que promueve el ser y actuar de las mujeres protagonistas de su propia historia. Está relacionado con lo personal y con lo social, con la posibilidad de "una experiencia eróticamente satisfactoria" (Lorde, 1994: 440), en todos los espacios de la vida. Como lo explica Lorde, "en la celebración de lo erótico en todos nuestros esfuerzos, mi trabajo se convierte en una decisión consciente - un anhelada cama, a la que voy con gratitud y de la que me levanto con más poder" (Lorde, 1994: 438). El impulso erótico conduce por lo tanto a una conexión con todas las cosas que fortifica nuestra búsqueda por mutualidad y, a través de la realización de esta búsqueda, nuestro esfuerzo por establecer justicia en todos los relacionamientos, no solamente en aquellos que expresan nuestra sexualidad (Clarck, 2012: 34).

Para la aplicabilidad de este criterio como clave hermenéutica, hay que dar el salto, esto significa buscar en los espacios de la transgresión los contenidos para nutrir el discurso teológico, rompiendo con la conceptualización que ha desvirtuado la categoría de las mujeres pobres, clausurándolas a una visión romántica y universal (Althaus-Reid, 2005: 57), de mujeres madres, reproductoras, cuidadoras y trabajadoras, exclusivamente heterosexuales, pero no deseosas y protagonistas de sus relaciones amorosas. Por lo tanto, la aplicabilidad del erótico como sagrado, posibilita incorporar una visión crítica de la demonización del cuerpo y del erotismo en las versiones oficiales del judaísmo-cristianismo (Pereira, 2001: 7). Como también posibilita la mirada crítica hacia el sistema de consumo que expropia la sensualidad y el erotismo utilizando de un lenguaje porno erótico (Lorde, 1994: 438).

Como lo hemos afirmado, la teología es discurso y es representación. Representación de un imaginario. Por eso que apuntar al erótico como sagrado exige creatividad para mirar lo que hasta ahora estuvo silenciado, demonizado, pero también sirve para denunciar lo que no funciona, tales como los contenidos de la teología cristiana que durante siglos se han nutrido del imaginario heterosexual masculino (Ruether, 1993: 51), muy puntualmente con toda su fuerza impositiva y normativa, incluyendo el control de la sexualidad de las mujeres.

La sexualidad, en general, ha sido tratada con los ejes de los perjuicios que sostienen cada sociedad. En general, el acto sexual es abordado para atrapar pervertidas(os) o irresponsables, o en un lenguaje mercadológico de consumo. Pero poco se habla de los placeres del sexo. A lo que todo indica, que hay una tendencia de idealización de la sexualidad y su perfección según el modelo hegemónico heterosexual, y lejos está el problematizar la falta de interés en él. La única posibilidad según este marco, es considerar el sexo hetero, muy bien comportado, que lleva en cuenta la fidelidad y la higiene. Todo lo que va más allá de esto no es discutido o no se refleja acerca de la complejidad de la realidad sexual humana, donde lo erótico, es parte efectiva. Y este es el punto, cuando se reivindica la sacralidad del erótico. Pues, el contacto con el erótico estimula a una condición crítica, dispuesta a cuestionar la naturalización de papeles y comportamientos tales como la resignación, la desesperación, la auto-destrucción, la depresión, la auto-negación (Lorde, 1994: 441), que implica en cambios de paradigmas mediados por rupturas epistemológicos apropiados.

\section{Nuevos sentidos con una imagen antigua}

A la par de la pintura de Coubert me gustaría invitarles a otra mirada o a revisitemos la imagen de la vulva, rescatemos de otro sentido de la misma. En la mitología griega, recorriendo el universo simbólico de diosas y arquetipos, propongo el rescate de una antigua historia, donde "Baubo, una sirvienta humilde que en el mito de Démeter y Perséfone sacó a la Diosa madre de su depresión, consecuencia del rapto de su preciosa hija por Hades, el dios del submundo" (Ress, 2007: 11). Hay algo de curioso en esta historia, pues Démeter, la gran diosa de los granos y de las cosechas, era también madre dedicada de Perséfone. Su indignación frente al rapto de la hija y a la indiferencia de los dioses varones, la conduce a una depresión intensa, que castiga la tierra con 
sequia y hambre por largo tiempo y queda entregada a su propio sufrimiento e impotencia. Pero, es justamente en este contexto que surge Baubo frente a Démeter, inconforme con la postración de la gran diosa. "Al levantar su falda y exponer su vulva, Baubo hizo reír a Démeter, haciéndola recordar que la vida seguiria adelante, que habrá otro amanecer - a pesar de todo" (Ress, 2007: 11). El gesto atrevido de Baubo frente a Démeter fue la salida, el renacimiento de la diosa. "Al sustituir la rabia por la risa, Baubo ofreció a la diosa la posibilidad de encontrar su energía sexual y regeneradora" (Ress, 2007: 11).

Quizás en este punto debamos detenernos, para aclarar que "el gesto de Baubo tiene su origen en los tiempos pre patriarcales, cuando la vulva fue vista como la puerta sagrada desde donde viene toda la vida" ( Ress, 2007: 11). Pero, en este gesto hay algo muy actual que tiene que ver con la resistencia de las mujeres latinoamericanas y caribeñas, que en su aislamiento, vergüenza, depresión, sufrimiento, logran y lograrán sobrevivir frente al opresor violento y abusador, a patrones e hijos de patrones, a maridos amargados y posesivos. Hay que rescatar los espacios marginales de las mujeres y la transgresión desde la risa y de la sexualidad en los espacios de mujeres. Es desde estos espacios, que se puede destacar "la cualidad de la risa que Baubo podría provocar: una risa desde las entrañas, una risa que nunca se burla o hiere, la comprensión de experiencias vividas en común" (Ress, 2007: 11). Y más que todo, el lugar común de las mujeres: la vulva y su sentido, su significado, que afirma nuestra fuerza y nuestra capacidad de sobrevivir, a pesar de todo, gozosas y deseosas, subversivas en nuestras risas.

Para la Teología Feminista Latinoamericana, la vulva - el sexo - el goce - el cuerpo - la risa - la complicidad indican el punto del rescate de una temática que por años ha sido negada, pero que nos ha desafiado como clave epistemológica "para reescribir la ideología, la teología y la sexualidad desde los márgenes de la sociedad, de la iglesia y de las teologías sistemáticas" (Althaus-Reid, 2005: 15). Se trata de hablar por nosotras mismas, reestructurando las imágenes y los discursos teológicos para que se conviertan en las condiciones reales de todas aquellas que buscan el amor con ternura, dignidad y justicia.

Como teóloga, el desafío es de ubicarme permanentemente frente a los discursos hegemónicos, repensando a la teología que esté relacionada con las demandas sociales cuyas herramientas de análisis pasa por la igualdad de género, diversidad sexual, derechos de las mujeres, juntándose a esto fe, espiritualidad y cotidianidad. Solamente con posiciones políticas claras y con proyecto de sociedad que rescata la justicia, la igualdad y la dignidad es que podemos escribir la teología feminista latinoamericana con algo de novedoso y liberador.

\section{Desde una pintura moderna-latinoamericana}

Siguiendo con la imagen de las pinturas, vale la pena rescatar un segundo cuadro. Se trata del cuadro de la pintora chicana Yolanda López. Así describe Althaus-Reid tal pintura:

Ésta [i.e. Yolanda López] ha pintado su autorretrato como surgida del manto abierto de la Virgen de Guadalupe, que, examinado con detenimiento, tiene la apariencia de una gigantesca vulva abierta. La imagen de la Virgen de Guadalupe ha sido descrita en términos alusivos al color oscuro de la piel de la imagen y al estilo de su vestimenta, aunque, curiosamente, no se ha dicho nada de esa tierna, turgente y rojiza vulva de la que emerge. López, como Virgen de Guadalupe, surge de esa divina vulva con aspecto de joven latina, con falda moderna y zapatillas deportivas, y en actitud de correr (Althaus-Reid, 2005: 73-74).

La pintura de López, relacionando la Virgen - el manto - la vulva - y la mujer latinoamericana, es explícita en su objetivo de actualizar la imagen de la Virgen de Guadalupe rompiendo con patrones clásicos que fijan al imaginario mariológico, estereotipos y nociones comportamentales. Es desde el manto sagrado, metafóricamente representado por una vulva, que surge la Virgen. El manto es la misma epifanía, es el mismo Dios. Un Dios representado por una vulva no puede ser leído como un Dios masculino. En otras palabras, 
se trata de la actualización del discurso acerca de Dios y de la Virgen, del quehacer teológico que se permite pensar con otros códigos, antes relegados y condenados como el no lugar, o como el obsceno y herético. Como lo ha relacionado AlthausReid en el análisis de la obra pictórica de López con la teología:

Podemos considerar por ejemplo, si Dios es una divinidad femenina representada por una vulva, pero yendo aún más allá, si Dios guarda relación con una sexualidad autónoma o reflejada (como en el caso de la sexualidad de las mujeres en la heterosexualidad tradicional). $O$ es Dios un lugar placentero, un punto $G$ doquiera oculto, pero establecido alrededor de proporciones miticas (a veces exageradas)? (Althaus-Reid, 2005: 74).

La imagen que está propuesta por AlthausReid, nos conduce a dos puntos muy revelantes: 1) confrontarnos con el horror inicial que hemos comentado desde la pintura de Courbet, y que está presente en nuestras culturas y nuestros imaginarios, con relación a la vulva. O sea, que imaginar a Dios desde la imagen plástica de la vulva, suena como algo imposible, obsceno, o como una herejía bajo los oídos de muchas mujeres y hombres. 2) La condición de reflexionar acerca de Dios, de lo que Es lo que Es, y está más allá que cualquier forma humanamente idealizada. Pero el punto es el de atrevernos a reflexionar acerca de la teología, desconstruyendo los ejes centrales ayer utilizados por las teologías sistemáticas que se permitían solamente a la representación de Dios con imágenes masculinas. Y más, rescatar la sacralidad del cuerpo de las mujeres desde la estética pero también desde el significado, pero transcendiendo a el mismo, para encontrar paradigmas más satisfactorios en la elaboración de la teología feminista latinoamericana. No se trata de limitarse a una clave de lectura, a una metáfora, a una imagen, pero más bien desde el punto prohibido restablecer la conexión de las mujeres con los discursos sobre Dios, problematizando las claves hermenéuticas que conducían a sola una cosmovisión.

Al recoger el ícono "María-Virgen" desde la sexualidad de las mujeres, se está juntamente problematizando la teología, porque hay en ellos implicaciones teísticas directas. Todavía más cuando se trata de la asociación entre virgen-virginidad-vulva-genitalidad-femenina-deseo-placer, o sea, que hay varios elementos conectados, antes separados, pero que requieren valor para actualizarlos y redefinírlos, desde la tradición cristiana con el ícono de la Virgen María. Al cuestionar los discursos mariológicos, también se problematiza los discursos teísticos, cristológicos, dado que su identidad es relacional y pone en duda las tradiciones de los presupuestos sexuales, proceso que al ser público, adquiere implicaciones políticas de transformación (Althaus-Reid, 2005: 104).

El cuadro de López, lo que infiere es una nueva mirada que destituye el imaginario teológico falocéntrico:

[...] el sexo no implica necesariamente diseminaciones penetrantes, como el retrato de la artista como Virgen de Guadalupe parece indicar. El punto G no necesita ser ubicado como suplemento; el punto $G$ pertenece a la vulva y a su placer, al abrazo de sus labios y a la dureza del clítoris. A partir de esta indiferenciada posición sexual podemos pensar acerca de nosotras mismas, como retrato de la teóloga en guisa de Virgen de Guadalupe y su reto a reconsiderar la posición sexual de Dios. (AlthausReid, 2005: 74-75).

Al elegir el cuadro de López como punto de partida para un análisis teológico desde el sexo de las mujeres latinoamericana, Althaus-Reid lo que hace es revelar como nosotras estamos atadas al simbolismo religioso de siglos y siglos, que nos inhibe de pensar más allá, por las identificaciones que nos fueron impuestas. Pero la identidad, la identificación es un compromiso que exige el "cuestionar el orden político y social creado alrededor de semejante ideología religiosa" (AlthausReid, 2005: 76). Exige rehacer las lecturas que nos han sido impuestas reinventando sentidos e imágenes desde la "piel sudada de hombres y mujeres pobres: dolorosos y gozosos, benditos y malditos (Pereira, 2006: 8).

Al insistir en la vulva como clave hermenéutica para la teología feminista latinoamericana, se presenta la consigna de protesta y se reafirma 
cambios de paradigmas, evocando el femenino plural, deconstruyendo íconos de auto-regulación y exigiendo una teología que indica que vivimos un tiempo donde se requiere de la capacidad de articulación compleja de los conocimientos. No nos sirve la simplificación y las antiguas respuestas reduccionistas y naturalizadoras de ideas y comportamientos hegemónicos.

La teología es la actualización de los discursos teísticos, y si así lo es, hay todavía un largo camino para ser hecho en la teología feminista latinoamericana con el enfrentamiento a las contradicciones: fe, búsqueda de comprensión, angustia, crítica, reinvención de sentidos.

Para una teología identificada con los sujetos, en este caso, con las mujeres empobrecidas de Latinoamérica y Caribe se trata de un reposicionamiento pues:

Las pobres son raramente vírgenes, porque pobreza en Latino-América significa condiciones atiborradas de violencia y promiscuidad en las que las muchachas son violadas antes de la pubertad o casadas en la adolescencia como parte de las pocas transacciones económicas en oferta disponibles, exceptuando algunas formas de prostitución y esclavitud sexual. Así, las mujeres quedan preñadas antes de saber qué sexualidad es la suya, antes de que puedan descubrir la divinidad del deseo en sus vidas (Althaus-Reid, 2005: 76).

Para la Teología Feminista Latinoamericana, al rescatar la dura realidad de las mujeres empobrecidas, debe aplicar la vieja premisa de la Teología de la Liberación, cuya afirmación es: "la teología es solo el segundo acto" (Segundo, 1982: 77), porque el primer es la propia vida vivida con sus grandezas y sus miserias, con la fe y el sentir del propio cuerpo.

\section{Conclusión}

Lo que hemos planteado en este breve artículo es la consideración de la hermenéutica en la Teología Feminista Latinoamericana con una clave de lectura interpretativa, cual sea el punto inicial: la vulva. Hay que considerar que la hermenéutica con todas sus posibilidades de comprensión es un tipo de perversión, que debe ser comprendida como otra versión, o en otras palabras, en la elección de otro camino, o como decirlo, un camino alternativo al modelo hegemónico heterosexual y patriarcal (Althaus-Reid, 2005: 104).

Al empezar la discusión teniendo como punto de partida a la vulva, lo que propongo es justamente el camino alternativo: 1) de quitar el horror a la vulva, culturalmente ocultando la cultura de violencia que de ella se ha apoderado, 2) considerar la vulva como clave epistemológica para la Teología Feminista Latinoamericana, desde la resistencia de las mujeres y de sus derechos, 3) deconstruir imaginarios simbólicos que han impuestos a las mujeres una teología que las niega, y a la totalidad de sus cuerpos y de sus deseos, 4) Recrear el discurso teológico, desde el horror y el ocultamiento de la vulva, pero rescatando la sacralidad, la subversión, la resistencia y la vida.

Al considerar la vulva como el punto de partida para la reflexión desde la teología feminista, lo que se propone es la apertura de lo inédito, al poner en duda las tradiciones de los presupuestos sexuales, proceso que al ser público puede tener implicaciones políticas de transformación" (Althaus-Reid, 2005: 104), pero también con disposición para dialogar. ¿Qué significa eso? Significa que la Teología Feminista Latinoamericana se atreve a elaborar nuevas preguntas, explorando nuevos significados, con sus propias claves hermenéuticas. También significa que la epistemología feminista se propone a la desconstrucción de lo que se considera como verdades únicas. Por esta razón, cuando se utiliza el eje inicial, la vulva, no se trata sencillamente del cuerpo biológico, sexual, individual, ni tampoco se trata del porno erótico, mercadológico. Sino tiene que ver con la creatividad para presentar lo que antes no se miraba, con valor suficiente para denunciar las opresiones y violencias, buscando caminos de liberación a las mujeres, incluyendo las "relaciones cotidianas y la fetichización de los deseos y de las necesidades" (Pereira, 2006: 7).

El conjunto complejo que nos conduce la reflexión teológica feminista, desde nuestra 
sexualidad, es mucho más que conferir importancia a la feminidad. Si se propone la reflexión desde la vulva, se hace necesario que reparemos en el clítoris, es decir, en la reintroducción del principio del placer a la discusión teológica, desde el ser de las mujeres (Althaus-Reid, 2005: 109), y de las nuevas formas de abusos y violencia, como por ejemplo, la violencia doméstica, la trata de personas, muy especialmente de mujeres jóvenes, niñas y travestis, de las condenas religiosas y públicas al aborto, etc. Para la Teología Feminista Latinoamericana son temáticas muy amplias, y casi inexploradas, donde "la Biblia y la teología dejan de ser una identidad auto-referente en los métodos sociológicos y histórico-críticos y pasan a convivir con el vértigo de la pluralidad de los paradigmas: clase, género, etnia, ecología" (Pereira, 2006: 7-8) y sexualidad.

El control patriarcal de los cuerpos eróticos de las mujeres estuvo presente desde el inicio de la colonización, nutriendo un imaginario de permanente dicotomía entre deseo y amor. Al denunciar estas formas de imposición, se da juntamente la liberación y los cambios, y a este punto llegamos, en el universo marginal, subversivo donde se encuentran las mujeres en solidaridad, organización y risas.

Reflexionar críticamente acerca del horror que se nos ha impuesto con relación a la imagen de la vulva, es cuestionar fuertemente el sistema de opresión que nos ha alienado a todas. Como lo explicita Pereira: "la alienación no es la negación del cuerpo sino la expropiación de la sensualidad y del erotismo al servicio de la apropiación del producto" (Pereira, 2006: 5). Por esta razón, se entiende la producción del cuadro de Courbet y su utilización por hombres famosos, incluyendo a Lacan, donde la vulva pasa a ser fetiche y adquiere sentido en el lenguaje porno erótico.

La vulva, como clave epistemológica para la Teología Feminista Latinoamericana, es una exigencia desde la resistencia de las mujeres, a cualquier hecho de dominación o regulación de cuerpos, pensamientos y fe, abriendo caminos para "el campo de la creación cultural, estética de memorias, hermenéutica de liberación" (Pereira, 2006: 8).

Confrontar el horror a la vulva surge como la posibilidad de la revisión de postulados, de creencias, de falacias, apuntando a nuevas prácticas y compromisos socio-políticos, pero, también ejerciendo el poder de recrear las metáforas teísticas que sostienen nuestra fe cristiana y estimula a seguir el camino de re-invención de la vida, por eso, tan relevante el título: el origen del mundo. El rescate, al mostrar la vulva (como lo hizo Baubo) es de la risa liberadora y solidaria, que encuentra sentido sacro en los deseos que pulsan como benditos.

\section{Referencias}

Althaus-Reid, Marcella. (2005). La Teología Indecente: perversiones teológicas en sexo, género y política. Barcelona: Bellaterra.

Althaus-Reid, Marcella. (2003). The Queer God. Canadá: Routledge.

Althaus-Reid, Marcella. (2004) From Feminist Theology to Indecent Theology: eadings on Poverty, Sexual Identity and God. Londres: SCM.

Althaus-Reid, Marcella. (2006). Liberation Theology and Sexuality. Burlington/USA: Ashgat.

Althaus-Reid, Marcella. (2002). O direito a não ser direita (el derecho a no ser derecha): sobre teologia, Igreja e pornografia. Concilium: Revista Internacional de Teologia. Petrópolis: Vozes, $n^{\circ} 298$, p. 95(671)-104(680).

Althaus-Reid, Marcella. (2006a). De la teología de la liberación feminista a la Teología Torcida. En: Cardoso, Nancy, Eggert, Edla y Musskopf, André S. (orgs.) A graça do mundo transforma Deus: Diálogos latino-americanos com a IX Assembléia do CMI. Porto Alegre: Editora Universitária Metodista.

Althaus-Reid, Marcella. (2007). Maria. Living la vida loca: Reflexões sobre os amores ilegais de Deus e a defesa da vida. Ribla, Petrópolis, n. 57, 80-85.

Althaus-Reid, Marcella. (2008). Yo soy la desintegración. En: EGGERT, Edla (Org.) [Re]leituras de Frida Kahlo: Por uma ética estética da diversidade machucada. Santa Cruz do Sul: EDUNISC, p. 94-100.

Althaus-Reid, Marcella \& Isherwood, Lisa. (2004). The Sexual Theologian - Essays on Sex, God and Politics. London: T\&T Clark International. 
Brum, Eliane. (2013). Por que a vagina provoca horror? En: Revista Época, disponible en: <http://revistaepoca.globo.com/Sociedade/eliane-brum/noticia/2012/06/porque-imagem-da-vagina-provoca-horror.html>

Carvalhaes, Cláudio. (2010). O pobre não tem sexo. A ausência dos discursos de sexualidade na construção da noção de subjetividade na Teologia da Libertação. Disponible: <http://www.claudiocarvalhaes.com/pt-br/ articles-pt-br/o-pobre-nao-tem-sexo/?lang=pt-br>

Clarck, John Michael. (2012). Sex, Earth \& Death in Gay Theology. Canadian Journal Under Currents, 1994, p. 34-39. Disponible en: <http://transecoqueer.wordpress. com/2010/06/06/sexo-terra-e-morte-na-teologia-gay >.

Comunicado Cero. (2013). La Diosa Griega Baubo. Disponible: en http://comunicadocero.blogspot.com/2010/05/ladiosa-griega-baubo.html>

Courbet, Gustave. (2013). L'Origine du monde. Disponible: <en http://spain.intofineart.com/usa/oil-painting-reproduction-Courbet, $\% 20$ Gustave--LQQQQQOrigine $\% 20$ $\mathrm{du} \% 20$ monde.html>

Deifelt, Wanda.(2003). Maria: uma santa protestante? En: Revista de Interpretação Bíblica Latino-Americana Maria. Petrópolis: Vozes, n. 46, p. 119-134.

Deifelt, Wanda. (2011). Interculturalidade, Negociação de Saberes, Educação Teológica: contribuições da teologia feminista. En: Protestantismo em Revista. São Leopoldo: EST, v. 24.

Gadamer, Hans-Georg.(1999). Verdade e Método - traços fundamentais de uma hermenêutica filosófica. Petrópolis: Vozes.

Guattari, Félix. (1991). As três ecologias. 3 ed. Campinas: Papirus.
Guattari, Félix; rolnik, Suely. (2005). Micropolítica: cartografias do desejo. Petrópolis: Vozes.

Kottow, Andrea. (2013). La figura de la pérdida como catástrofe del individuo contemporáneo en la trilogía Un animal mudo levanta la vista de Germán Marín: Una lectura desde Peter Sloterdijk. En: Acta Literaria, n. 41, Concepción, 2010, Disponible en: $<$ http://www.scielo.cl/scielo.php?script=sci_arttext\&pid $=$ S0717-68482010000200003>

López, Yolanda. (2010). Portrait of the Artist as the Virgin of Guadalup. Disponible: <http://mati.eas.asu.edu/ChicanArte/html_pages/lopez11.html>

Lorde, Audre. (1994). Lo erótico como poder. En : Del cielo a la tierra. Una antologia de Teologia Feminista. Chile : Sello Azul, p. 438-451.

Pereira, Nancy Cardoso.(2001). Sagrados corpos. Introdução: Sagrados corpos. Revista de Interpretação Bíblica Latino-AmericanalRibla, Petrópolis: Vozes, n. 38, p. 5-10.

Pereira, Nancy Cardoso. (2006). Entre la erótica y la barbárie. Espiritualidad feminista en tiempos de mercado. En: Con-spirando - Erotismo y espiritualidad. No. 53, p. 4-10.

Ress, Mary Judith.(2007). "Cuando no hay visiones, el pueblo muere" Una vuelta más sobre las intuiciones ecofeministas. En: Con-spirando Revista Latinoamericana de Ecofeminismo, espirituralidad y teología. Santiago: Editorial Latinoamericano, n. 57, p. 8-18.

Ruether, Rosemary R. (1993). Sexismo e Religião: Rumo a uma teologia feminista. São Leopoldo: Sinodal.

Segundo, Juan Luis.(1982). Fe e ideología (El hombre de hoy ante Jesús de Nazaret I). Madrid: Cristandad. 
- 